\title{
Utility of solution X-ray scattering for the development of antibody biopharmaceuticals
}

\author{
Hideyo Inouye $^{1 \#}$, Damian Houde ${ }^{2 \dagger}$, Deniz B.Temel ${ }^{2 *}$ and Lee Makowski ${ }^{1,3 \dagger}$ \\ ${ }^{1}$ Department of Electrical and Computer Engineering, College of Engineering, Northeastern University \\ ${ }^{2}$ Protein Pharmaceutical Development, Biogen \\ ${ }^{3}$ Department of Chemistry and Chemical Engineering, Northeastern University

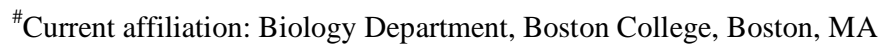 \\ *Current affiliation: Amgen Inc., Thousand Oaks, CA
}

$†$ Corresponding authors: Lee Makowski and Damian Houde

\begin{abstract}
Characterization of immunoglobulin ( $\mathrm{IgG})$ solutions at high concentrations represents a significant challenge. A current trend in the biopharmaceutical industry is to manufacture highly concentrated drug products, which can be used to deliver high doses in small volumes, via subcutaneous injections. Studying a molecule's structure and properties in its final drug product formulation is ideal. But, characterization is typically performed under dilute solution conditions with critical stabilizing buffer components removed because of interference effects, which can result in an incomplete understanding of the molecule's properties. Direct study of protein conformation and protein-protein interactions in concentrated solutions challenging for most biophysical and biochemical techniques; however, x-ray solution scattering offers opportunities. Combined with other biophysical techniques, $\mathrm{x}$-ray scattering has the potential to provide relevant information on both structure and interactions in protein solutions over a broad concentration range. Here, we report x-ray solution scattering of four monoclonal antibodies, designated mAb1 (glycosylated and de-glycosylated), mAb2, and mAb3 at concentrations between 0.5 and $>168 \mathrm{mg} / \mathrm{ml}$. Data acquired from these measurements are combined with the results from other biophysical measurements to generate a comprehensive profile of their solution behaviors. Our results show that $\mathrm{x}$-ray solution scattering can assess key parameters needed to aid in formulation development.
\end{abstract}

Key words: immunoglobulin, $\mathrm{x}$-ray scattering, protein-protein interaction, second virial coefficient, aggregation number 


\section{Introduction}

A growing number of immunoglobulin (IgG) recombinant monoclonal antibodies (mAbs) are being used as therapeutic agents at high concentration (1-3). However, high protein concentrations can give rise to high viscosity, tendency to aggregate or undergo phase separation, and other forms of deterioration that, with time, can represent significant obstacles in the development of efficacious, stable, and safe therapies (4). Characterization of highly concentrated protein solutions represents a significant challenge as most biophysical and biochemical techniques are performed under dilute solution conditions. Ideally, the relationship between protein structure, formulation, viscosity, aggregation, and potency must be studied in the relevant formulation environment. This is often not possible because of buffer and or protein concentration interference effects, thus direct analysis of highly concentrated mAb formulations is difficult and there are very few techniques capable of analyzing such samples. As a result, most analysis is performed on dilute samples in buffers selected to avoid interference with the technique as opposed to being formulation-relevant. The resulting data are then extrapolated to higher concentrations. Unfortunately studies of proteins in dilute solution are not always representative or predictive of the behaviors of proteins at high concentrations. Furthermore, a direct correlation of the properties measured at low concentration to those properties at high concentrations is difficult because of experimental constraints (e.g., limited dynamic range).

X-ray and neutron scattering techniques have the potential for characterizing highly concentrated solutions. Although the use of small angle x-ray scattering (SAXS) for determining size and shape of a protein has traditionally been performed on dilute solutions (approximately $\leq 1 \mathrm{mg} / \mathrm{mL}(5,6)$ ), its application has been extended to study protein-protein interactions at higher concentrations $\geq 10 \mathrm{mg} / \mathrm{mL}$ $(7,8)$ and at very high concentrations of $\geq 100 \mathrm{mg} / \mathrm{mL}$ (9-14). Additional information on protein structure and flexibility in its secondary structure can be extracted from x-ray solution scattering in the wide-angle (WAXS) regime (15). These scattering techniques have been used for studies of IgGs, including measurement of the second virial coefficient $\left(A_{2}\right)(14)$, analysis of heterogeneous multiple monomeric conformers $(16,17)$, and aggregates $(18)$. It is also worth noting that solution x-ray scattering experiments are buffer independent. While background buffer scans are taken and subtracted from the protein solution, a direct comparison between proteins in different solution matrices can be performed. This may be particularly relevant in the area of protein formulation development, where many different buffer solutions and excipients are studied for determining conditions that offer optimal stability. Additionally, SAXS may also benefit biosimilar comparability. Since it is very likely that the manufacturer of a biosimilar will have its molecule formulated in a different buffer matrix than the innovator molecule, the 
buffer matrix will not interfere with the analysis and a direct comparison between two proteins in different buffers is possible (19).

In this study, we analyzed the higher-order structure, protein-protein interactions and colloidal properties for glycosylated and deglycosylated forms of an IgG1 (designated mAb1), a glycosylated form of a second IgG1 (mAb2), and a glycosylated IgG4 (mAb3). All but mAb2 were studied in optimal formulation conditions (i.e., conditions that demonstrated favorable long-term stability) and with a concentration range between 3 and $>150 \mathrm{mg} / \mathrm{ml}$. mAb2 lacked the solubility required to achieve concentrations in excess of $\sim 20 \mathrm{mg} / \mathrm{ml}$, but was included in these experiments to demonstrate the diversity of solution conditions and molecular behaviors of closely related molecules that SAXS is capable of studying. We show that $\mathrm{mAb} 1$ and $\mathrm{mAb} 3$ proteins were solubilized in a monomeric form to high concentrations due to long-range repulsion between the proteins as indicated by the positive value of $A_{2}(11,14,20,21)$. MAb2 however exhibits a negative $A_{2}$, indicating that the interaction between the proteins is attractive, consistent with our observation of limited solubility and aggregation that increases with concentration. To this end we also correlate $A_{2}$ data derived from SAXS observations with $k_{D}$ values determined from dynamic light scattering (DLS). This correlation, which has not yet been investigated in detail for different mAbs provides some validation for extrapolating to high concentration effects observed in low concentration $k_{D}$ measurements. Moreover, analysis of protein solutions by SAXS is traditionally performed at synchrotron sources because the quality of the data is related to the intensity of the x-ray source (higher intensity sources produce higher quality data). However, the intensity of lab source x-ray generators has increased dramatically over the past years and data quality comparable to synchrotron sources is possible. To demonstrate this, we carry out a detailed comparison of data collected at a synchrotron source to those collected on a lab x-ray source and found the data to be highly comparable. These data support the utility of x-ray scattering as a characterization tool for proteins in support of biopharmaceutical characterization and comparability (i.e., the ability to consistently manufacture a product).

\section{Methods}

\section{Antibodies and Reagents}

All of the antibodies studied in this work (mAbs 1-3) were overexpressed in Chinese hamster ovary cells $(\mathrm{CHO})$ and were highly purified and prepared in optimized formulation buffer at different 
concentrations, from 0.5 to $>150 \mathrm{mg} / \mathrm{mL}$. All concentrations were measured by UV-vis and refractive index, repeat measurements were used to determine the accuracy to be within $\pm 0.05 \mathrm{mg} / \mathrm{mL}$. All mAbs were studied in their expressed glycosylated forms. In addition, samples of deglycosylated mAb1 were generated by incubation of native mAb with N-Glycosidase F (PNGase F) for $20 \pm 2$ hours at $\mathrm{pH} \sim 7$, at $37^{\circ} \mathrm{C}$ (Prozyme, San Diego, CA, USA). All chemicals and reagents were purchased from Sigma-Aldrich (St. Louis, MO, USA) unless otherwise mentioned.

\section{Sample preparation of IgGs for SAXS}

mAb1 samples were formulated in $10 \mathrm{mM}$ sodium citrate, $\mathrm{pH} 6.3,150 \mathrm{mM}$ L-arginine $\mathrm{HCl}$ $(\mathrm{ArgHCl})$, and $0.05 \%(\mathrm{w} / \mathrm{v})$ polysorbate-80. Different concentrations of this molecule prepared from 10 to $150 \mathrm{mg} / \mathrm{ml}$. Concentration range for $\mathrm{mAb} 2$ was from $0.5 \mathrm{mg} / \mathrm{ml}$ to $20 \mathrm{mg} / \mathrm{ml}$, formulated in $10 \mathrm{mM} \mathrm{Na}$ Phosphate, $\mathrm{pH} 6.2,10 \%$ sucrose and $0.01 \%$ polysorbate- 80 . MAb3 was prepared from $3 \mathrm{mg} / \mathrm{ml}$ to 168 $\mathrm{mg} / \mathrm{ml}$ in $50 \mathrm{mM}$ sodium phosphate and $100 \mathrm{mM} \mathrm{NaCl}$ at $\mathrm{pH} 6.0$ with and without $0.04 \%$ polysorbate- 80 . The formulations for mAb1 and mAb3 represent the conditions that provided optimal long term stability. Whereas, the formulation for $\mathrm{mAb} 2$ was not developed and was chosen because we felt that it helped to show the breadth of information that solution x-ray scattering could deliver.

\section{Synchrotron Solution $x$-ray scattering and analysis}

SAXS data were collected using the undulator-based beam line X9 at the National Synchrotron Light Source (NSLS) at Brookhaven National Laboratory (BNL) configured with two detectors in order to collect SAXS and WAXS data simultaneously, over the range of $0.01<q<2.0 \AA^{-1}$, where $q$ is the momentum transfer ( $q=4 \pi \sin \theta / \lambda), 2 \theta$ the scattering angle and $\lambda$ the wavelength of incident X-rays (22). Data were collected at an X-ray wavelength of $0.9184 \AA$ A. A Photonic Science CCD detector operated as the WAXS detector and a Mar 165 CCD as the SAXS detector. The SAXS detector was located $3.4 \mathrm{~m}$ from the sample. Samples were loaded into a 96-well plate and aspirated into the $1.5 \mathrm{~mm}$ diameter, thin-walled sample tube using an automated system (22). Protein flow rate past the x-ray beam was adjusted to limit protein exposure to x-rays to less than $100 \mathrm{~ms}$ in order to eliminate radiation damage $(15,23)$. Temperature of the protein solutions was maintained at $11^{\circ} \mathrm{C}$ in the sample holder and the scattering chamber. Preliminary data processing was carried out using the $\mathrm{X} 9$ software package to produce circularly averaged intensity profiles. The $q$-range was extended by combining data from the two detectors. The observed intensity was corrected for the scattering from capillary tube, buffer, windows and slits according to the methods described by Makowski et al. (15). In order to compare the observed intensities of the IgG solutions in the small angle regime at different protein concentrations, the 
curves were scaled over the range $q=0.075-0.17$ (1/Å) according to the method reported by Mosbaek et al. (14), and the distance distribution function $P(r)$ was scaled at $r=45 \AA$. The processed data were examined using the display programs in the ATSAS program suite (24).

Computer programs from the ATSAS software suite distributed by European Molecular Biology Laboratory (EMBL) were used for analyzing diffraction data, including GNOM (25), AUTOGNOM, AUTOPOROD (26) for determining the radius of gyration $\left(r_{g}\right)$, the maximum size and volume of protein in solution and distance distribution function respectively; CRYSOL for calculating the x-ray solution scattering intensity from the atomic coordinates (27); and DAMMIF (28) for reconstruction of the three-dimensional protein structure. For three-dimensional reconstructions of the molecular envelope, ten reconstructions were calculated and averaged using DAMAVER (29).

The reported atomic coordinates of IgGs were obtained from the protein data bank (PDB) and included glycosylated human IgG1 against HIV-1, 1HZH (30), glycosylated anti-canine lymphoma monoclonal antibody IgG2a, 1IGT (31), and glycosylated monoclonal antibody for phenobarbital IgG1, 1IGY (32). The secondary structure propensity, secondary structure prediction from a clustering method of amino acid composition, distributions of physical-chemical characteristics including charge, hydrophobicity, polarity, number of electrons and molecular weight were estimated using PROTEIN (33). The atomic models of heavy and light chains of the $\operatorname{IgG}$ molecules were predicted on the basis of homology with $1 \mathrm{HZH}$ structure (30) and the amino acid sequences of the proteins using SWISS-MODEL (34).

\section{Lab-source solution scattering and analysis}

SAXS experiments were performed using a 2D Kratky camera, the BioSAXS-2000, and a 96well Automatic Sample Changer controlled by SAXSLab software (Rigaku Americas Corporation, The Woodlands, TX, USA). X-rays were supplied by an FR-X microfocus rotating anode X-ray generator configured with a confocal multilayer OptiSAXS optic. All SAXS images were recorded on a Dectris PILATUS 100K detector. The BioSAXS-2000 was aligned to capture the $q$ range of 0.008 to $0.68 \AA^{-1}$. Prior to SAXS measurements, all sample dilutions were centrifuged at $15,000 \mathrm{x}$ g for $10 \mathrm{~min}$ at $4^{\circ} \mathrm{C}$ using a microcentrifuge. Aliquots (70 $\mu \mathrm{l})$ of sample dilutions and buffers were loaded into a 96-well low-profile PCR plate and the plate was placed in the Automatic Sample Changer. For all concentrations, sample and buffer conditions, measurements were made using $30 \mathrm{~min}$ of total exposure with an image recorded every 5 min to inspect for radiation damage. All data were collected in a temperature controlled sample holder 
at $10^{\circ} \mathrm{C}$. Data were processed automatically, starting from the SAXS images, by SAXSLab. Additional processing was performed as indicated above.

\section{Dynamic light scattering from protein solutions}

Diffusion coefficients were measured with respect to protein concentration on a DynaPro PlateReader Plus (Wyatt Technology, Santa Barbara, CA, USA) at a laser wavelength of $828.88 \mathrm{~nm}$. Aliquots of the filtered $(0.22 \mu \mathrm{m}) \mathrm{mAb}$ samples were transferred into sterile, 96-well, clear-bottom plate Greiner Sensoplates (Greiner Bio-One, Monroe, NC, USA). Wyatt Technology Dynamics software (v. 7.3.6) was used to schedule and automate 50 independent $5 \mathrm{sec}$ scans for each sample. Three replicates $(n=3)$ were averaged to reduce statistical errors in the sample preparation and analysis. Measurements were performed at $25^{\circ} \mathrm{C}$. The average mutual translational diffusion coefficients, $D_{m}$, determined for each $\mathrm{mAb}$ solution at protein concentrations between 1 and $20 \mathrm{mg} / \mathrm{mL}$ were plotted as a function of concentration. The interaction term, $k_{D}$, was obtained from the slope of these plots using a linear regression analysis, while the y-intercept provided the value for $D_{0}$ at zero concentration $(m=0)$.

\section{Theory}

In the supplementary material, we include a brief synopsis of the theory of $\mathrm{x}$-ray scattering from concentrated protein solutions; derivation of interference function and its relationship to scattered intensity; the definition of $A_{2}$, and its estimation from scattering data; and the relationship of $D_{m}, k_{D}$, and $A_{2}$ to one another.

\section{Results}

\section{SAXS patterns}

Figure 1 includes SAXS data from all the mAbs collected over a range of protein concentrations. Figure 1A contains traces of the small angle data and Figure 1B is the data extending to wider angles. Since the scattered intensity is proportional to the number of electrons in the exposed sample, the observed intensities increase in proportion to the number of protein molecules in the scattering volume (i.e., protein concentration). The wide angle scattering (Figure 1B) exhibits peaks at $\sim 1 / 10 \AA$ and $\sim 1 / 4.7$ $\AA$ spacing $\left(\mathrm{q} \sim 0.6\right.$ and $\left.1.4 \AA^{-1}\right)$, characteristic of the inter-sheet and inter-chain distances found in $\beta$ - 
sheets. The presence of these peaks is indicative of a homogeneous population of molecules with welldefined secondary structure, which is consistent with the fold within an IgG monomer, as $\beta$-strands are typically separated by approximately $4.7 \AA$. Similar peaks have been observed in protein fibrils (35). However, that is not the case here because in fibrils, the $\beta$-strands are oriented perpendicular along the axis of the fibrils and the $4.7 \AA$ reflection is typically quite sharp, reflecting the coherence length of the fiber, which is typically hundreds of $\AA$. The breadth of the $4.7 \AA$ peaks in Figure 1 for these mAbs corresponds to a coherence length of $\sim 30 \AA$, within the expected size range of a single beta sheet within a single protein. These wide angle peaks are poorly defined in $\mathrm{mAb} 2$, indicating that the protein exhibits significantly more flexibility in its secondary structure than observed in the other mAbs, significantly different structural organization, or is structurally heterogeneous. Figure 1C displays the small angle intensities after re-scaling on the basis of wide-angle data in order to estimate the scattering per protein particle as required for estimation of the interference function (see Supplementary Material). Once rescaled, the largest difference in scattering among samples at different protein concentrations is observed at low reciprocal coordinate $q$. Figure 1D displays the ratio of each intensity distribution with that derived from the lowest concentrated sample (since the lowest concentrated sample will exhibit the smallest amount of interference due to interparticle interference and will thereby be the closest approximation to the square of the structure factor, $F^{2}(q)$, (See Supplementary Material equation S1 For mAb1 $10 \mathrm{mg} / \mathrm{mL}$ was used (1 and $10 \mathrm{mg} / \mathrm{mL}$ analysis of mAb1 resulted in highly comparable SAXS profiles, Figure S1A and B), for mAb2 $0.5 \mathrm{mg} / \mathrm{mL}$ was used, and for $\mathrm{mAb} 33 \mathrm{mg} / \mathrm{mL}$ was used (1 and 3 $\mathrm{mg} / \mathrm{mL}$ of mAb3 resulted in highly comparable SAXS profiles, Figure S1C). Scattering intensity from the solution of lowest concentration is the weakest, thereby exhibits the greatest noise level. Since it is present in the denominator of the equation for the interference function it leads to the relatively high noise levels observed in Figure 1D. The radial distribution function, $g(r)$, for each protein is plotted and shown in Figure 1E.

\section{Observed intensities}

For the glycosylated mAb1, scattering was collected from samples with protein concentrations of $10,50,75,100,125$, and $150 \mathrm{mg} / \mathrm{ml}$. Intermolecular interactions are best detected by comparison of the scaled intensity curves (Figure 1C). Scaled intensity decreases as protein concentration increases in the small angle scattering from glycosylated mAb1. This depression is due to a change in inter-particle interference and indicates a repulsive interaction among the protein monomers. 
For the deglycosylated mAb1, scattering exhibited similar trends to the glycosylated mAb1 although the nature of the interference function is clearly different as can be seen in Figure 1D where the interference function displays a maximum at small $\mathrm{q} \sim 0.01 \AA^{-}{ }^{1}$.

For mAb2 scattering data were collected at concentrations of $0.5,1,2,5,10$ and $20 \mathrm{mg} / \mathrm{ml}$ (Figure 1A). The features in the wide angle scattering (Figure 1B) are indistinct compared to those observed in scattering from mAb1 or mAb3. The two intensity maxima at $q=0.6$ and 1.4 arising from the inter-sheet and hydrogen-bonding distances in the $\beta$-sheets of the $\operatorname{IgG}$ fold are very diffuse and not nearly as prominent as those of $\mathrm{mAb} 1$ and $\mathrm{mAb} 3$ proteins, suggesting substantial flexibility in the secondary structures in mAb2. Scaled intensities exhibit a trend with protein concentration which is opposite in trend to that of mAb1 or mAb3 with the largest intensity at low q being observed for the highest protein concentration. This is caused by the attractive nature of forces among the mAb2 molecules as will be detailed in the consideration of $\mathrm{A}_{2}$ below.

For mAb3, the scattering intensities were recorded at protein concentrations of 3, 10, 50100 , $120,168 \mathrm{mg} / \mathrm{ml}$ in two different buffers. Similar to mAb1, the intensity of mAb3 protein solution at the lowest concentration (in this case $3 \mathrm{mg} / \mathrm{ml}$ ) exhibited the strongest scaled intensity at small angles. At the origin, the interference function varied according to protein concentration independent of buffer used.

\section{Radial distribution function}

The radial distribution function, $g(r)$, is a measure of the probability of a scattering particle being a distance $r$ from a reference protein. This function is zero for $r=0$, since two proteins cannot occupy the same position simultaneously. For hard spherical proteins $g(r)$ would be a step function, zero for $r$ less than twice the particle radius, and 1.0 for larger radii. For proteins with complex shapes such as IgGs, $g(r)$ starts at zero and rises gradually, approaching a value of 1.0 at $r$ greater than the largest interatomic vector in the protein. The radial distribution function is calculated directly from the interference $S(q)$ as in Supplementary Material equation S3.

The distance between nearest neighbor particles ( $a$ ) was measured from the observed interference peak at the reciprocal coordinate at $q_{p} \sim 0.05 \AA^{-1}$ using the relations of $R_{p}=q_{p} / 2 \pi$ (Figure 1D) and $a R_{p}=1.23(10)$. The nearest neighbor distance for glycosylated mAb1 was found to be larger than that of the deglycosylated mAb1 (Figure 2A), reflecting a greater repulsion between mAbs when the glycan is present. The neighboring distance of $\mathrm{mAb} 2$ was nearly constant at different protein 
concentrations (Figure 2B), while the distance between molecules of mAb3 and mAb1 decreased with an increase in concentration (Figure 2A and 2C).

\section{Second virial coefficient for protein solutions}

As discussed in the Supplementary Material, the second virial coefficient, $\mathrm{A}_{2}$, provides a measure of the strength of intermolecular interactions within a protein solution and SAXS can be used to estimate $A_{2}$ using data as a function of protein concentration. Figure $2 \mathrm{D}-\mathrm{F}$ are plots of $1 / \mathrm{S}(0)$ as a function of protein concentration for the four mAbs studied here, and the second virial coefficient is proportional to the slope of these plots (14). While only two concentrations are needed to generate a line, three to five concentrations should be analyzed to generate more accurate data. In our study, these included a relevant low concentration $(1-10 \mathrm{mg} / \mathrm{mL})$ along with the final targeted drug product concentration $(\sim 10-200$ $\mathrm{mg} / \mathrm{mL}$ ) and a few additional concentrations in between. The concentrations will depend on the molecule being studied.

mAb1: The dependence of $1 / S(0)$ as a function of concentration (Figure 2D) was used to determine $A_{2}$ (see equation S6 in Supplementary Material) for glycosylated $\left(2.93 \times 10^{-5}\right.$ ) and deglycosylated mAb1 $\left(1.89 \times 10^{-5}\right)$. The positive value indicates the presence of repulsive protein-protein interactions for both samples, with the glycosylated protein exhibiting greater repulsion. The data suggest that $\mathrm{A}_{2}$ is roughly a constant over the range of concentrations studied $(50-150 \mathrm{mg} / \mathrm{ml})$ as indicated by a linear regression curve.

mAb2: Contrary to that observed for mAb1, the scaled intensities of scattering from mAb2 increased with concentration in the small angle regime, the highest intensity being observed for the 20 $\mathrm{mg} / \mathrm{ml}$ solution, while the lowest one was for the solution at $0.5 \mathrm{mg} / \mathrm{ml}$ (Figure 1C). 1/ $S(0)$ was plotted as a function of protein concentration (Figure 2E). Fitting the curve to a second order polynomial derived from equation S6 in the Supplemental Material section (see equation 1 below):

$$
1 / S(0)=1+2 A_{2} M c+3 A_{3} M c^{2}+\bullet \bullet \bullet,
$$

equation 1

The second virial coefficient $A_{2}$ was estimated as $-1.35 \times 10^{-4}\left[\mathrm{~mol} . \mathrm{cm}^{3} / \mathrm{g}^{2}\right]$, the negative value indicating the presence of attractive forces between particles. The curvature of the $1 / S(0)$ plot indicates that the attractive forces among proteins moderate as protein concentration increases. 
mAb3: The1/S(0) plot as a function of concentration for glycosylated mAb3 exhibited a slope of approximately 2.78 leading to a calculation of $A_{2}=4.97 \times 10^{-6}$ (Figure 2F). Compared to mAb1, this constitutes a very weak repulsion, approximately $20 \%$ of that for mAb1.

\section{Solution structures of IgG molecules}

There are few crystal structures of intact and full length $\operatorname{IgG}$ molecules. At least three different forms of full length IgGs have been crystallized and the atomic coordinates reported (Figure 3, S2-S4). Each IgG molecule has three domains, two of which are variable regions comprised of both light and heavy chains, and one of which is the constant region formed by the constant regions of two heavy chains. Flexible linkers connect variable and constant regions making possible a wide range of different configurations of the three domains, reflected in the different crystal structures. Comparing the radii of gyration for 1IGT $\left(r_{g}=54 \AA\right.$ ) with those of $1 \mathrm{HZH}\left(r_{g}=52 \AA\right)$ and $1 \mathrm{IGY}\left(r_{g}=47 \AA\right)$ indicates that $1 \mathrm{IGY}$ has the most compact structure (Figure 3A). It is interesting to note that an mAb molecule (i.e., 1HZH), which is chemically symmetric, crystallized in a non-symmetric conformation. This was originally thought to be an artifact of the crystal contacts, but reconstructions of IgG structures from solution scattering suggest that even in solution, in the absence of crystal contacts, an asymmetric structure is often preferred (Figure S2-S4 and Table S1).

mAb1: The distance distribution function, $P(r)$, and a three dimensional molecular envelope of glycosylated mAb1 (Figure 3B) was calculated using standard methods with the software package ATSAS (24) using the observed intensity at $10 \mathrm{mg} / \mathrm{ml}$ (note that 1 and $10 \mathrm{mg} / \mathrm{mL}$ data resulted in the same structure, Figure S1A and S1B). The distance distribution function $P(r)$ of mAb1 is very similar to the one calculated from the atomic coordinates in the pdb file 1HZH (Figure 3). $P(r)$ calculated from other available atomic coordinate sets for full length IgGs (1IGY and 1IGT) are somewhat different, indicates that the solution structure of mAb1 most closely resembles that of $1 \mathrm{HZH}$. The low resolution SAXS reconstruction of mAb1 was superimposed manually on the atomic coordinates of a homology model of mAb1 constructed by SWISS-MODEL (34) through a search using 1HZH as a template (Figure 3). The agreement was excellent, providing further evidence that mAb1 in solution takes on a structure closely corresponding to that of $1 \mathrm{HZH}$.

$P(r)$ was also calculated from scattering patterns of glycosylated and deglycosylated mAb1 over a range of concentrations (Figure $4 \mathrm{~A}$ and B). Although a calculation of $P(r)$ is usually limited to low concentrations where it will provide information on the structure of individual proteins, it can be 
calculated for any concentration and provide information about distortion of the autocorrelation function of the sample by intermolecular interactions. In this case, $P(r)$ at higher concentrations exhibits an increasingly strong peak at $\mathrm{r} \sim 25 \AA$, indicative of interparticle interactions and potential distortion of the molecules at these higher concentrations.

mAb2: The distance distribution function $P(r)$ for protein solutions at different concentrations (Figure 4C) and the three dimensional envelope for $\mathrm{mAb} 2$ at $0.5 \mathrm{mg} / \mathrm{ml}$ (Figure 3C) was calculated from the observed intensity as described above. Interestingly, even at $0.5 \mathrm{mg} / \mathrm{ml}$, the protein shows signs of oligomerization, with the $P(r)$ extending well beyond the expected maximum radius of approximately 200 $\AA$ (Figure 3C). The reconstructed molecular envelope also exhibits features corresponding to a much larger volume than expected for a monomer (Figure 3C). The interpretation of the features in the molecular envelope reconstructed from this data is unclear since assumptions required for successful reconstruction of molecular envelopes break down in the presence of partial oligomerization as appears to be the case here.

To further investigate the oligomerization of $\mathrm{mAb} 2$, we calculated the volume ratio $\xi$ for the protein defined in equation 2 :

$$
\xi(c)=v(c) / v\left(c_{0}\right)=r_{g}^{3}(c) / r_{g}^{3}\left(c_{0}\right)
$$

equation 2

where $c_{0}=0.5 \mathrm{mg} / \mathrm{ml}, v$ is volume of the low resolution envelope and $r_{g}$ is radius of gyration. This volume ratio can also be interpreted as the aggregation number. The radius of gyration derived from the Guinier plot and GNOM methods were averaged and provided an independent measure of the volume ratio. The volume ratio (i.e., aggregation number) was nearly 1 at $1-2 \mathrm{mg} / \mathrm{ml} ; 2$ at $5 \mathrm{mg} / \mathrm{ml}$; and 3 at 10 to $20 \mathrm{mg} / \mathrm{ml}$, indicating that number of monomers in the aggregates is concentration dependent, and corresponds to monomer, dimer and trimer at these respective concentrations. This agrees with the $P(r)$ calculated at these concentrations (Figure 4C) showing a single major peak at about $r=50 \AA$ for $1-2$ $\mathrm{mg} / \mathrm{ml}$, two peaks at $50 \AA$ and $200 \AA$ in $5 \mathrm{mg} / \mathrm{ml}$, and three peaks at $50 \AA, 200 \AA$, and $350 \AA$ in 10 and 20 $\mathrm{mg} / \mathrm{ml}$ protein solutions. These data also correlate with earlier studies by Wei et al. (36).

mAb3: A three dimensional reconstruction of the molecular envelope was carried out (Figure 3D and S1C) and distance distribution functions calculated from the observed intensity of mAb3 at $3 \mathrm{mg} / \mathrm{ml}$, and compared with those from the IgG atomic coordinates, 1HZH, 1IGT and 1IGY. The $P(r)$ indicates that mAb3 takes on a conformation most similar to $1 \mathrm{HZH}$, but that even at these concentrations inter- 
particle interactions are present and observable, leading to a long tail in the $P(r)$ that extends beyond $\mathrm{r}$ $=150 \AA$ A. $P(r)$ calculated from intensities collected at different protein concentrations (Figure 4D) confirm that intermolecular interactions give rise to a high-radius tail in $P(r)$ that increases in extent with increasing protein concentration and is indicative of a change in conformation. The interparticle interactions also obscure the interpretation of the molecular envelope shown in Figure 3D.

\section{Diffusion coefficient by dynamic light scattering}

mAb1: The second virial coefficient $A_{2}$ can be related to the interaction parameter, $k_{D}$, obtained from DLS measurements using empirical relationships put forward by Connolley et al. (4) as briefly described in the Supplementary Material. The mutual diffusion coefficient was measured using DLS for concentrations of $1-20 \mathrm{mg} / \mathrm{ml}$ for glycosylated $\mathrm{mAb} 1$ resulting in an estimate for the interaction parameter $k_{D}$ as $56.71 \mathrm{~mL} / \mathrm{g}$ (Figure 5A). Lehermayr et al. (37) documented a linear dependence of $\mathrm{k}_{\mathrm{D}}$ on $\mathrm{A}_{2}$ and provided an empirical relationship between the two for a set of IgG1 and IgG4 mAbs. Connolley et al. (4) carried out an independent study of IgG1s that obeyed a similar (though distinct) relationship shown in Supplementary Material equation S10. Use of any of these relationships with our $k_{D}$ measurements results in an estimate of $A_{2}$ in the range of $2.72-3.45 \times 10^{-4}$. These values are significantly larger than measured from $\mathrm{x}$-ray scattering $\left(\sim 2.93 \times 10^{-5}\right)$, suggesting that the empirical relationships, as derived and used for low concentration solutions, may not be readily applied to $A_{2}$ measurements for more highly concentrated solutions. Since $A_{2}$ is a measure of the non-ideality of the solution, one would expect it to increase with concentration. This discrepancy highlights the distinct ways proteins interact in dilute and concentrated solutions. As will be shown below, this discrepancy does not extend to the other mAbs studied here. The relationship between these measurements and the predictions of the linear, empirical equation suggests that the linear relationship breaks down at extremes of either $k_{D}$ or $A_{2}$.

Similar measurements on the deglycosylated mAb1 (Figure 5A) resulted in an estimate of the interaction parameter of $-2.17 \mathrm{~mL} / \mathrm{g}$. This corresponds to an $A_{2}=3.64 \times 10^{-5}$ from empirical equation $\mathrm{S} 9$ (see Supplementary Material), consistent with the $A_{2}$ measured from x-ray scattering for glycosylated $\left(2.93 \times 10^{-5}\right)$ and deglycosylated $\mathrm{mAb} 1\left(1.89 \times 10^{-5}\right)$. In this case, our data appears to behave as predicted by the empirical relationship derived previously. The deglycosylated mAb1 has a smaller $A_{2}$ value than the glycosylated, indicating that the protein-protein interaction for the glycosylated mAb1 is more repulsive than that for the deglycosylated form. 
$\mathrm{mAb2}$ : DLS measurement of the diffusion interaction parameter of mAb2 resulted in a value of $k_{D}=-27$ (Figure 5A) leading to an empirical estimate of the value for $A_{2}$ of $-0.95 \times 10^{-4}\left[\mathrm{~mol} . \mathrm{cm}^{3} / \mathrm{g}^{2}\right]$ for the hydrated glycosylated mAb2 (IgG1) in close correspondence to that obtained by x-ray scattering ($\left.1.35 \times 10^{-4}\left[\mathrm{~mol} . \mathrm{cm}^{3} / \mathrm{g}^{2}\right]\right)$. Unlike the measurements taken for $\mathrm{mAb} 1$, the concentration ranges over which these two measurements were made were nearly identical and the estimates of $A_{2}$ derived from x-ray scattering and $k_{D}$ from DLS (via the empirical relationship established earlier) are very similar.

mAb3: The second virial coefficient derived from x-ray was $A_{2}=4.97 \times 10^{-6}$ (Figure 2F). This estimate may be compared with the diffusion coefficient (Figure 5A) through the empirical linear relationships introduced recently $(4,37)$. Use of those relationships (Supplementary Material equation S9 and S10) with the DLS data in Figure 5A results in approximations of $A_{2} \sim 1.37$ or $2.67 \times 10^{-5}$ respectively, which are somewhat larger than the $A_{2}$ measured from x-ray scattering.

Except for glycosylated $\mathrm{mAb} 1$, the empirical relationship between interaction parameter $k_{D}$ and $A_{2}$ appear to hold. This is evident by the linear relation between $k_{D}$ derived from DLS and $A_{2}$ from x-ray scattering shown for mAb1, mAb2 and $\mathrm{mAb} 3 \mathrm{IgG}$ proteins (Figure 5B).

\section{Comparison of SAXS data from synchrotron and lab sources}

The scattering intensity distributions of $\mathrm{mAb} 1$ at 10 and $100 \mathrm{mg} / \mathrm{ml}$ were measured using both a lab source x-ray generator (Rigaku, BioSAXS) and a synchrotron (BNL) and the data were directly compared. The two intensities for both 10 and $100 \mathrm{mg} / \mathrm{ml}$ samples were scaled so that the intensities at

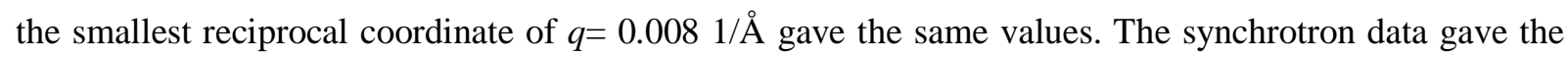
intensity to $q=1.8$, while the lab source gave intensity values to $q=0.7$. Both intensities were nicely superimposed, while the intensity data from the lab source showed larger error bars at wide angle region (Figure A6). The intensity data after subtracting the intensity scattered by the buffer were measured for $\mathrm{mAb} 1$ at concentrations of $1,5,10,25,50$ and $100 \mathrm{mg} / \mathrm{ml}$ and the first order visibility was similar to that of the synchrotron (data not shown). The pixel size used for the lab source was also comparable with that of the synchrotron at lower angle range.

The distribution functions, $P(r)$ for glycosylated and deglycosylated mAb1 and mAb3 were also determined from the lab source data. The molecular envelopes were then determined using the DAMMIF program and the structures fit nicely around the atomic coordinates of the mAb crystal structure, similar to the synchrotron results (Figure 7). 


\section{Excluded volume and charge effects}

The $A_{2}$ in these solution x-ray scattering studies was derived from the slope $(m)$ of $1 / S(0)$ as a function of protein concentration. $A_{2}$ can also be calculated from the excluded volume $(u)$ and number of surface charges ( $Z$ ) (38) assuming spherical geometry. Spherical symmetry is obviously a poor approximation for IgG shape, but since the calculation derives from long-range hydrodynamic effects, the requirement of spherical shape to obtain analytical solutions may not be as inappropriate as it might originally seem. Given that the net pair-potential is dependent on exclusion, repulsion, and attraction, which are effective in separate ranges of distance between particles, i.e., very short range effect by the excluded volume, long range effect by electrostatic repulsion, and short range effect by attraction, $A_{2}$ may be written as (equation 3):

$A_{2}^{e x}=\frac{N u}{2 M^{2}}=\frac{N}{2 M^{2}} \bullet\left(\frac{32}{3}\right) \pi r_{e}^{3}$ equation 3

$m=2 M A_{2} \approx \frac{N}{M} \cdot\left(\frac{32}{3}\right) \pi r_{e}^{3}+\frac{1000 Z^{2} v_{1}}{2 m_{3} M}+2 M A_{2}^{a}$

where $A_{2}^{e x}$ is the second virial coefficient arising from the excluded volume, $m$ is the slope of a linear regression curve for $1 / S(0)$ as a function of concentration, the second term of $m$ arises from the electrostatic repulsion, $A_{2}^{a}$ is from an attractive potential, $N$ is Avogadro's number, $M$ is molecular weight of the solute particle, $r_{e}$ is effective radius. Since the first two repulsion terms are positive, and the last term of attractive $A_{2}^{a}$ is negative, the condition of colloidal stability may be defined by a greater repulsion than attraction between particles according to (equation 4):

$$
\frac{N}{M} \bullet\left(\frac{32}{3}\right) \pi r_{e}^{3}+\frac{1000 Z^{2} v_{1}}{2 m_{3} M}>\left|2 M A_{2}^{a}\right|
$$

equation 4

Equations 3 and 4 indicate that when the effective radius and surface charge are increased, the colloidal stability is increased. The increase in the ionic strength of the buffer medium decreases the colloidal stability by shielding the surface charge. 
Inverting these arguments, we can derive the surface charge from the above equations and the experimentally determined $A_{2}$ measured by x-ray scattering. The choice of an effective radius of a nonspherical structure like an IgG1 is problematic. Among three different radii utilized for this model (hydrodynamic radius, radius of gyration, and the radius calculated from the known molecular weight and specific volume), the hydrodynamic radius provides the most accurate $A_{2}(39)$. Therefore, we choose a diameter of $110 \AA$ for an IgG (i.e., twice the hydrodynamic radius). The $A_{2}$ of a short range attraction was not measured here, but can be assumed to be close to the value of $-6.5 \times 10^{-5}$ at $\mathrm{pH} 6.5$ (40) as determined for IgG particles solubilized in solutions at high ionic strength.

If we choose $M=179 \mathrm{kDa}$ (for the hydrated protein), and the measured value of $m=10.5$ for the hydrated glycosylated $\mathrm{mAb} 1$ and $M=175 \mathrm{kDa}$ and $m=6.6$ for the hydrated deglycosylated $\mathrm{mAb} 1$ (Figure 2D), ionic strength of the medium $m_{3}=0.18$ (see supplementary material for the ionic strength calculation), specific volume of the medium $v_{1}=1, A_{2}^{a}=-6.5 \times 10^{-5}(\mathrm{ml})(\mathrm{mol}) / \mathrm{g}^{2}(40)$ and the effective radius of $r_{e}=110 / 2 \AA$ from the hydrodynamic radius (39), the number of charges can be calculated from the above equations to be $Z=+31$ for the glycosylated $\mathrm{mAb} 1$ and $Z=+25$ for the deglycosylated mAb1. A larger charge number estimated for the glycosylated mAb1 than that of deglycosylated accounts for a larger $A_{2}$ and a larger distance between the neighboring particles due to an increase in the electrostatic repulsion force (Figure 2A). The charge numbers calculated for both types of protein are smaller than $Z=$ +35 as estimated from the amino-acid sequence (Figure S5), suggesting that not all ionizable residues are exposed to the surface of the protein (10). In an alternate calculation, if the charge numbers for both glycosylated and deglycosylated protein are assumed to be the same value of $Z=+31$, the effective radius becomes $55 \AA$ for the glycosylated, and $50 \AA$ for the deglycosylated proteins. This could indicate that the Fc domain is collapsed due to deglycosylation (which is consistent with previous work), giving rise to a closed form of $\mathrm{Fc}$ with smaller radius of gyration $(41,42)$ that may be stabilized in the deglycosylated mAb1. A linear trend of $1 / \mathrm{S}(0)$ as a function of protein concentration (Figure 2D) for both glycosylated and deglycoslylated mAb1s can be explained by that fact that the sugars are not surface oriented, and that the sugar residues are likely not interacting with other molecules. While glycan removal has been shown by structural techniques such as, nuclear magnetic resonance (NMR) (43) and hydrogen/deuterium exchange mass spectrometry (HDX-MS) $(44,45)$ to change the local environment, conformation, and dynamics of mAbs (i.e., within the Fc region), the overall structure and shape of a mAb upon glycan removal is largely unaffected. For mAb1, global HDX-MS analysis along with circular 
dichroism (CD), and analytical ultracentrifugation (AUC) was performed and all data were highly comparable between glycosylated and deglycosylated states (data not shown).

In a similar calculation for glycosylated $\mathrm{mAb} 2$ in solution with the ionic strength of 0.01 , the number of charges is estimated as $Z=+14$ to account for $m=-48$ (or $A_{2}=-1.35 \times 10^{-4}$ ) and a radius of 55 $\AA$. This estimated number of charges is slightly smaller than the number of charges of $Z=+18$ as estimated from the amino acid sequence of mAb2 (Figure S6). For glycosylated mAb3 in solution with 0.15 ionic strength and $A_{2}=0.93 \times 10^{-5}$ the effective number of charges of $Z=+20$ accounts for the radius of $55 \AA$. This estimated charge number is quite similar to $Z=+22$ as estimated from the amino acid sequence (Figure S7). These calculations indicate that the underlying reason that the protein-protein interaction is repulsive for $\mathrm{mAb} 1$ and $\mathrm{mAb} 3$, and attractive for $\mathrm{mAb} 2$ is that the former two proteins have larger surface charges than $\mathrm{mAb} 2$. In order to choose the $\mathrm{pH}$ and ionic strength so that the protein solution can be stabilized, the relation in equation 4 may be used from the known number of charges from the amino acid sequence, and the $A_{2}$ values of exclusion volume and attraction. Additionally, equation (3) suggests that the repulsive protein-protein interaction is dependent on the radius of hydrated protein particle and the surface charge. If the surface charge can be derived satisfactorily from the amino acid sequence, then the electrostatic repulsion could be calculated with a given ionic strength. When the $A_{2}$ value is determined by experiment from the two SAXS data at a low (e.g., $1 \mathrm{mg} / \mathrm{ml}$ ) and at a higher concentration, the radius of hydrated protein, and then the excluded volume effect can be determined by equation (3).

\section{Discussion}

We demonstrate in the present study that SAXS can characterize a range of phenomena in protein solutions of widely varying concentration in which the principal protein-protein interactions are either attractive or repulsive. Estimation of the interference function provides substantial insight into the nature of protein-protein interactions. If the concentration of a protein solution is low, the distance between protein particles is large enough that scattered x-ray waves from different protein particles do not interfere, thus the scattered intensity observed is proportional to that of a single protein particle. For mAb1, our observations indicate that interference did not exist at concentrations $\leq 10 \mathrm{mg} / \mathrm{mL}$. This was evident because the calculated distance distribution function of $P(r)$ is similar to the one derived from the atomic coordinates of $1 \mathrm{HZH}$, and the 3D reconstruction agreed well with the atomic coordinates of the 
$1 \mathrm{HZH}$ crystal structure. By contrast, even at the lowest protein concentration the x-ray scattering from $\mathrm{mAb} 2$ and $\mathrm{mAb} 3$ exhibits signs of inter-particle interference, which confounds the calculation of protein shape. Analysis of the solution scattering from these mAbs indicates that the protein-protein interaction is repulsive for mAb1 (both glycosylated and deglycosylated) and mAb3, but attractive for mAb2. The extent of repulsion was greater for glycosylated mAb1 than deglycosylated mAb1. These differences are reflected in the $A_{2}$ values and may be caused by differences in the excluded volume and/or charge distributions of these biomolecules (see below).

\section{Comparison with previous solution x-ray diffraction studies of IgG proteins}

Previous solution x-ray studies on therapeutic antibodies at high concentration include human anti-EGFR IgG2 antibody, panitumumab (Vectibix@ produced by Amgen) at 3.2-122 mg/ml (14). Their formulation medium contains physiological saline with/without high amounts of sucrose $(270 \mathrm{mM})$ at $\mathrm{pH}$ 5.8. This formulation is distinctly different from the buffer medium used for the mAbs studied here. While the mAb1 3D model is similar to $1 \mathrm{HZH}$ crystalline structure, the anti-EGFR IgG2 antibody, panitumumab is similar to IIGY, the most compact structure among three crystalline atomic models considered here (see Figure 3). Mosbaek et al. (14) obtained the interference function from x-ray scattering, and estimated the $A_{2}$ to be $2.06-4.96 \times 10^{-5}(\mathrm{~mol})(\mathrm{ml}) / \mathrm{g}^{2}$ which is similar to our current estimate for mAb1. These values are also consistent with $A_{2}$ derived from the empirical relation between the $k_{D}$ and $A_{2}$, where the measured $k_{D}$ for anti-EGFR IgG2 antibody panitumumab was in the range between -4.18 and $-8.86 \mathrm{ml} / \mathrm{g}(14)$.

Different conformers of monomer were considered before in order to account for the solution scattering of IgG1 type of monoclonal antibodies at concentrations of 1, 2.5 and $5 \mathrm{mg} / \mathrm{ml}$ (16). In that study, the observed intensity was accounted for by a monomeric protein alone, and indicated that $\mathrm{Arg} \mathrm{HCl}$ shifts the equilibrium between two conformations, altering the angle between the two Fab domains to favor the open conformation over the closed conformation. The study by Lilyestrom et al. (16) did not explore the effect of $\mathrm{Arg} \mathrm{HCl}$ on solublization of the concentrated $\operatorname{IgG}$ (46). Many different conformations of monomer (10 for IgG1 mAbs, 5 for IgG2 mAbs, and 7 for IgG4 mAbs) are proposed to account for the observed solution scattering (17), by applying ensemble optimization method (EOM) (47, 48). Our analysis of mAb1 demonstrated that a single conformer, similar to the one in the crystal structure of 1HZH but not 1IGT and 1IGY (Figure 3, S2 and Table S1), is sufficient to explain the observed intensity measured at $\leq 10 \mathrm{mg} / \mathrm{ml}$. This means that the particle structure factor measured from the SAXS intensity at low concentration is similar to the Fourier transform of the atomic coordinates of $1 \mathrm{HZH}$. The 
intensity distribution measured at higher concentration therefore, arises from the product of the squared particle structure factor and the inter-particle interference (equation S1). In this case, we do not assume conformational heterogeneity of protein molecule at any protein concentrations. A similar comparison was performed for mAb2 (Figure 3, S3 and Table S1) and mAb 3 (Figure 3, S4, and Table S1).

\section{Similar $2^{\text {nd }}$ virial coefficients measured from dilute and concentrated solutions}

The theory predicts that $A_{2}$ is not dependent on protein concentration, thus $1 / S(0)$ will be linearly related to the concentration in a protein solution up to the concentration where higher order terms become important (see equation S5 in Supplementary Material). At higher concentrations, a regression curve is no longer linear, and then not only $A_{2}$ but also $A_{3}$ (and potentially higher order terms) must be considered to account for observations. For mAb1 and mAb3 at concentrations up to $150 \mathrm{mg} / \mathrm{ml}$ only $A_{2}$ is required to account for the data reported here, whereas data from mAb2 exhibits linearity only to about $5 \mathrm{mg} / \mathrm{ml}$. This difference in behavior derives from the fact that intermolecular interactions of $\mathrm{mAb} 1$ and $\mathrm{mAb} 3$ in solution are repulsive, but for $\mathrm{mAb} 2$, they are attractive. While the dispersion of protein particles in solutions of $\mathrm{mAb} 1$ and $\mathrm{mAb} 3$ is likely homogeneous, the aggregation size of $\mathrm{mAb} 2$ is heterogeneous at all but the very lowest of protein concentrations, with a mixture of oligomeric species giving rise to a non-linear relation between $1 / S(0)$ and protein concentration.

$A_{2}$ has been measured routinely for dilute $\mathrm{IgG}$ solutions at concentrations of up to $20 \mathrm{mg} / \mathrm{ml}$ by light scattering techniques. An important question is whether the estimate of $A_{2}$ measured at these lower protein concentrations by light scattering is predictive of behavior at higher concentrations. Our x-ray measurements provide insight into this question by providing access to $A_{2}$ values in highly concentrated protein solutions. Our DLS measurements on mAb1 led to estimates of $A_{2}$ significantly higher than that obtained from x-ray scattering. By contrast, estimates of $A_{2}$ for deglycosylated mAb1 from light and xray scattering were very similar. This discrepancy for the glycosylated mAb1 between $k_{D}$ and $A_{2}$ can be explained by assuming that the surface charge and particle size vary with the protein concentration, i.e. a decrease in surface charge and/or a decrease in the radius of a hydrated protein at higher concentrations. For mAb3, the estimate of $A_{2}$ from light scattering was somewhat larger than that derived from x-ray data. These observations indicate that while light scattering from proteins in dilute solution may often provide estimates of $A_{2}$ that are valid at much higher concentrations, this will not always be the case. Other investigators have made similar observations when comparing the $A_{2}$ values from the mutual 
diffusion coefficient by DLS with those from x-ray diffraction $(11,49,50)$. From these observations we conclude that the form of intermolecular interactions may change as a function of concentration in ways that are difficult to anticipate from studies of dilute solutions, providing examples for the need for direct measurements on concentrated solutions.

\section{Conclusion}

This study confirms the merit of $\mathrm{x}$-ray solution scattering for characterizing the colloidal and structural stabilities of $\mathrm{mAb}$ proteins in concentrated solutions. While analysis of the second virial coefficient with SAXS data has been demonstrated previously (11), these data provide new insights into the diverse behavior of mAbs. MAb1 and mAb3 have been studied in formulations known to promote long term stability and $\mathrm{mAb} 2$ has been studied in a formulation with sub-optimal properties that exhibits concentration dependent oligomerization. X-ray solution scattering proved effective in discriminating the diverse behaviors of these molecules as well as providing guidance as to the molecular bases of their distinct behaviors. Comparison of measurements at low and high protein concentrations of these mAbs indicated that measurements in dilute solution were not always predictive of high concentration behavior. Direct biophysical measurements on concentrated formulations were indicated as necessary for full characterization of the structural and colloidal properties of the solutions. Consideration of the distribution of surface charges on the molecule suggested causal relationships between the charge distribution and colloidal behaviors.

\section{Acknowledgments}

The authors would like to Dr. Marek Kloczewiak for initiating the SAXS collaboration between Biogen and Northeastern University, as well as Dr. Andrew Weiskopf and Jessica Ballinger of Biogen for their continued support and encouragement. We would also like to thank Dr. Steven Berkowitz for many useful discussions. In addition, we would like to thank Dr. Mark DelCampo of Rigaku for acquiring the SAXS data on the BioSAXS-2000 lab source system. Use of the National Synchrotron Light Source, Brookhaven National Laboratory, was supported by the U.S. Department of Energy, Office of Science, Office of Basic Energy Sciences, under Contract No. DE-AC02-98CH10886.

\section{References}


1. Dani B, Platz R, Tzannis ST. High concentration formulation feasibility of human immunoglubulin $G$ for subcutaneous administration. Journal of pharmaceutical sciences. 2007;96(6):1504-17.

2. Scott AM, Wolchok JD, Old LJ. Antibody therapy of cancer. Nature Reviews Cancer. 2012;12(4):278-87.

3. Shire SJ, Liu J, Friess W, Jörg S, Mahler H-C, Hershenson F. High-concentration antibody formulations: John Wiley \& Sons, Inc: Hoboken, NJ, USA; 2010.

4. Connolly BD, Petry C, Yadav S, Demeule B, Ciaccio N, Moore JM, et al. Weak interactions govern the viscosity of concentrated antibody solutions: high-throughput analysis using the diffusion interaction parameter. Biophysical journal. 2012;103(1):69-78.

5. Hura GL, Menon AL, Hammel M, Rambo RP, Poole li FL, Tsutakawa SE, et al. Robust, highthroughput solution structural analyses by small angle X-ray scattering (SAXS). Nature methods. 2009;6(8):606-12.

6. Putnam CD, Hammel M, Hura GL, Tainer JA. X-ray solution scattering (SAXS) combined with crystallography and computation: defining accurate macromolecular structures, conformations and assemblies in solution. Quarterly reviews of biophysics. 2007;40(03):191-285.

7. Tian X, Langkilde AE, Thorolfsson M, Rasmussen HB, Vestergaard B. Small - Angle X - ray Scattering Screening Complements Conventional Biophysical Analysis: Comparative Structural and Biophysical Analysis of Monoclonal Antibodies IgG1, IgG2, and IgG4. Journal of pharmaceutical sciences. 2014;103(6):1701-10.

8. Frka-Petesic B, Zanchi D, MARTIN NC, Carayon S, Huille S, Tribet C. Aggregation of antibody drug conjugates at room temperature: SAXS and light scattering evidence for colloidal instability of a specific subpopulation. Langmuir. 2016.

9. Inouye H, Sharma D, Kirschner DA. X-ray Diffraction for Characterizing Structure in Protein Aggregates. Misbehaving Proteins: Springer; 2006. p. 167-91.

10. Inouye H, Tsuruta H, Sedzik J, Uyemura K, Kirschner DA. Tetrameric assembly of full-sequence protein zero myelin glycoprotein by synchrotron x-ray scattering. Biophysical journal. 1999;76(1):423-37.

11. Tardieu $A$, Le Verge $A$, Malfois $M$, Bonneté $F$, Finet $S$, Riès-Kautt $M$, et al. Proteins in solution : from X-ray scattering intensities to interaction potentials. Journal of Crystal Growth. 1999;196(2-4):193203.

12. Makowski L, Houde DJ, Berkowitz SA. Scattering Techniques for the characterization of biopharmaceuticals. In: Houde DJ, Berkowitz SA, editors. Biophysical Characterization of Proteins in Developing Biopharmaceuticals

Newnes; 2014. p. 171-210.

13. Fukuda M, Moriyama C, Yamazaki T, Imaeda Y, Koga A. Quantitative Correlation between Viscosity of Concentrated MAb Solutions and Particle Size Parameters Obtained from Small-Angle X-ray Scattering. Pharmaceutical research. 2015;32(12):3803-12.

14. Mosbæk CR, Konarev PV, Svergun DI, Rischel C, Vestergaard B. High concentration formulation studies of an IgG2 antibody using small angle X-ray scattering. Pharmaceutical research. 2012;29(8):2225-35.

15. Makowski L, Rodi DJ, Mandava S, Devarapalli S, Fischetti RF. Characterization of protein fold by wide-angle X-ray solution scattering. Journal of molecular biology. 2008;383(3):731-44.

16. Lilyestrom WG, Shire SJ, Scherer TM. Influence of the cosolute environment on IgG solution structure analyzed by small-angle X-ray scattering. The Journal of Physical Chemistry B. 2012;116(32):9611-8.

17. Tian X, Vestergaard B, Thorolfsson M, Yang Z, Rasmussen HB, Langkilde AE. In-depth analysis of subclass-specific conformational preferences of IgG antibodies. IUCrJ. 2015;2(1):9-18. 
18. Lilyestrom WG, Yadav S, Shire SJ, Scherer TM. Monoclonal antibody self-association, cluster formation, and rheology at high concentrations. The Journal of Physical Chemistry B. 2013;117(21):637384.

19. Berkowitz SA, Engen JR, Mazzeo JR, Jones GB. Analytical tools for characterizing biopharmaceuticals and the implications for biosimilars. Nature Reviews Drug Discovery. 2012;11(7):527-40.

20. Inouye H, Sharma D, Goux WJ, Kirschner DA. Structure of core domain of fibril-forming PHF/Tau fragments. Biophysical journal. 2006;90(5):1774-89.

21. Yearley Eric J, Zarraga Isidro E, Shire Steven J, Scherer Thomas M, Gokarn Y, Wagner Norman J, et al. Small-Angle Neutron Scattering Characterization of Monoclonal Antibody Conformations and Interactions at High Concentrations. Biophysical Journal. 2013;105(3):720-31.

22. Allaire M, Yang L. Biomolecular solution X-ray scattering at the National Synchrotron Light Source. Journal of synchrotron radiation. 2011;18(1):41-4.

23. Fischetti R, Stepanov S, Rosenbaum G, Barrea R, Black E, Gore D, et al. The BioCAT undulator beamline 18ID: a facility for biological non-crystalline diffraction and X-ray absorption spectroscopy at the Advanced Photon Source. Journal of synchrotron radiation. 2004;11(5):399-405.

24. Petoukhov MV, Franke D, Shkumatov AV, Tria G, Kikhney AG, Gajda M, et al. New developments in the ATSAS program package for small-angle scattering data analysis. Journal of applied crystallography. 2012;45(2):342-50.

25. Svergun D. Determination of the regularization parameter in indirect-transform methods using perceptual criteria. Journal of Applied Crystallography. 1992;25(4):495-503.

26. Petoukhov MV, Konarev PV, Kikhney AG, Svergun DI. ATSAS 2.1-towards automated and websupported small-angle scattering data analysis. Applied Crystallography. 2007.

27. Svergun D, Barberato C, Koch MHJ. CRYSOL - a Program to Evaluate X-ray Solution Scattering of Biological Macromolecules from Atomic Coordinates. Journal of Applied Crystallography. 1995;28(6):768-73.

28. Franke D, Svergun DI. DAMMIF, a program for rapid ab-initio shape determination in small-angle scattering. Journal of applied crystallography. 2009;42(2):342-6.

29. Volkov VV, Svergun DI. Uniqueness of ab initio shape determination in small-angle scattering. Journal of Applied Crystallography. 2003;36(3 Part 1):860-4.

30. Saphire EO, Parren PW, Pantophlet R, Zwick MB, Morris GM, Rudd PM, et al. Crystal structure of a neutralizing human IGG against HIV-1: a template for vaccine design. Science. 2001;293(5532):1155-9.

31. Harris $\sqcup$, Larson SB, Hasel KW, McPherson A. Refined structure of an intact IgG2a monoclonal antibody. Biochemistry. 1997;36(7):1581-97.

32. Harris L, Skaletsky E, McPherson A. Crystallographic structure of an intact IgG1 monoclonal antibody. Journal of molecular biology. 1998;275(5):861-72.

33. Inouye $\mathrm{H}$, Kirschner $\mathrm{D}$. Folding and function of the myelin proteins from primary sequence data. Journal of neuroscience research. 1991;28(1):1-17.

34. Schwede T, Kopp J, Guex N, Peitsch MC. SWISS-MODEL: an automated protein homologymodeling server. Nucleic acids research. 2003;31(13):3381-5.

35. Oliveira CLP, Behrens MA, Pedersen JS, Erlacher K, Otzen D, Pedersen JS. A SAXS Study of Glucagon Fibrillation. Journal of Molecular Biology. 2009;387(1):147-61.

36. Wei JY, Bou - Assaf GM, Houde D, Weiskopf A. Technical Decision - Making with Higher Order Structure Data: Detecting Reversible Concentration - Dependent Self - Association in a Monoclonal Antibody and a Preliminary Investigation to Eliminate It. Journal of pharmaceutical sciences. 2015;104(11):3984-9. 
37. Lehermayr C, Mahler HC, Mäder K, Fischer S. Assessment of net charge and protein-protein interactions of different monoclonal antibodies. Journal of pharmaceutical sciences. 2011;100(7):255162.

38. Tanford C. Physical chemistry of macromolecules. Journal of Pharmaceutical Sciences. 1962;51(2):190-.

39. Grünberger A, Lai P-K, Blanco MA, Roberts CJ. Coarse-grained modeling of protein second osmotic virial coefficients: sterics and short-ranged attractions. The Journal of Physical Chemistry B. 2013;117(3):763-70.

40. Roberts D, Keeling R, Tracka M, van der Walle C, Uddin S, Warwicker J, et al. The Role of Electrostatics in Protein-Protein Interactions of a Monoclonal Antibody. Molecular pharmaceutics. 2014;11(7):2475-89.

41. Borrok MJ, Jung ST, Kang TH, Monzingo AF, Georgiou G. Revisiting the role of glycosylation in the structure of human IgG Fc. ACS chemical biology. 2012;7(9):1596-602.

42. Krapp S, Mimura $Y$, Jefferis R, Huber R, Sondermann P. Structural analysis of human IgG-FC glycoforms reveals a correlation between glycosylation and structural integrity. Journal of molecular biology. 2003;325(5):979-89.

43. Yamaguchi $Y$, Nishimura M, Nagano M, Yagi H, Sasakawa H, Uchida K, et al. Glycoformdependent conformational alteration of the Fc region of human immunoglobulin $\mathrm{G} 1$ as revealed by NMR spectroscopy. Biochimica et Biophysica Acta (BBA)-General Subjects. 2006;1760(4):693-700.

44. Houde D, Arndt J, Domeier W, Berkowitz S, Engen JR. Characterization of IgG1 conformation and conformational dynamics by hydrogen/deuterium exchange mass spectrometry. Analytical chemistry. 2009;81(7):2644-51.

45. Houde D, Peng Y, Berkowitz SA, Engen JR. Post-translational modifications differentially affect IgG1 conformation and receptor binding. Molecular \& Cellular Proteomics. 2010;9(8):1716-28.

46. Inoue N, Takai E, Arakawa T, Shiraki K. Specific decrease in solution viscosity of antibodies by arginine for therapeutic formulations. Molecular pharmaceutics. 2014;11(6):1889-96.

47. Tria G, Mertens HD, Kachala M, Svergun DI. Advanced ensemble modelling of flexible macromolecules using X-ray solution scattering. IUCrJ. 2015;2(2):207-17.

48. Bernadó P, Mylonas E, Petoukhov MV, Blackledge M, Svergun DI. Structural characterization of flexible proteins using small-angle X-ray scattering. Journal of the American Chemical Society. 2007;129(17):5656-64.

49. Bonneté F, Finet S, Tardieu A. Second virial coefficient: variations with lysozyme crystallization conditions. Journal of crystal growth. 1999;196(2):403-14.

50. Bonnete F, Vivares D. Interest of the normalized second virial coefficient and interaction potentials for crystallizing large macromolecules. Acta Crystallographica Section D: Biological Crystallography. 2002;58(10):1571-5. 


\section{Figure Legend}

Figure 1. (A) Observed small angle intensities as a function of reciprocal coordinate $q[1 / \AA]$ for mAb1 (glycosylated and deglycosylated), mAb2 and mAb3 protein solutions. (B) Observed wide angle intensities as a function of $q$. (C) Small angle intensities after re-scaling over the range $q=0.076-0.17$ [1/Å]. The inset of mAb2 shows a plot of the small angle region. (D) Interference function as a function of $\boldsymbol{q}$. The squared structure amplitudes used to calculate the interference function were estimated from the observed intensities measured for $10 \mathrm{mg} / \mathrm{ml}$ glycosylated $\mathrm{mAb} 1,0.5 \mathrm{mg} / \mathrm{ml} \mathrm{mAb2}$ and $3 \mathrm{mg} / \mathrm{ml} \mathrm{mAb3}$ in PBS buffer. The mAb2 inset indicates polynomial regression curves. (E) Radial distribution functions for selected protein concentrations.

Figure 2. (A) Distance between the neighboring particles as a function of protein concentration $[\mathrm{g} / \mathrm{ml}]$ for glycosylated (blue) and deglycosylated mAb1 (red). Peak position was measured directly from the interference function. (B) Distance between the neighboring particles within the aggregates as a function of protein concentration $[\mathrm{g} / \mathrm{ml}]$ for $\mathrm{mAb} 2$. Peak position was measured directly from a 6th order polynomial regression curve of the interference function. The peak position was observed at $q=0.062$ $1 / \AA ̊$ for all concentrations studied. (C) Distance between the neighboring particles as a function of protein concentration $[\mathrm{g} / \mathrm{ml}]$ for $\mathrm{mAb} 3$. Peak position was measured directly from the interference function. (D) $1 / S(0)$ plot as a function of protein concentration $[\mathrm{g} / \mathrm{ml}]$ for glycosylated mAb11 (blue) and deglycosylated mAb1 protein (red). Lines were determined by linear regression. (E) Dependence of $1 / S(0)$ for $\mathrm{mAb} 2$ as a function of protein concentration in $\mathrm{g} / \mathrm{ml}$. A second order polynomial regression curve was calculated from all data points according to $1 / S(0)=1+2 A_{2} M c+3 A_{3} M c^{2}$. (F) $1 / S(0)$ plot as a function of $\mathrm{mAb} 3$ concentration in $\mathrm{g} / \mathrm{ml}$ with linear regression fit.

Figure 3. (A) Three dimensional models of IgG atomic coordinates 1HZH, 1IGT and 1IGY. (B) Two different orthogonal views of 3D reconstruction envelope in bead models (yellow) by DAMMIF for $10 \mathrm{mg} / \mathrm{ml} \mathrm{mAb1}$ protein. The space fill model of $1 \mathrm{HZH}$ atomic coordinates was superimposed. The distance distribution function as a function of distance $[\AA]$ was calculated for $10 \mathrm{mg} / \mathrm{ml} \mathrm{mAb} 1$ (blue) and structures of $1 \mathrm{HZH}, 1 \mathrm{IGT}$ and $1 \mathrm{IGY}$. The curves were scaled at $=45 \AA$. (C, D) Displays of reconstructed envelopes and distance distributions for $\mathrm{mAb} 2(0.5 \mathrm{mg} / \mathrm{ml})$ and $\mathrm{mAb} 3(3 \mathrm{mg} / \mathrm{ml})$.

Figure 4. Distance distribution functions for (A) glycosylated mAb1, (B) deglycosylated mAb1, (C) glycosylated mAb2, and (D) glycosylated mAb3 at different concentrations.

Figure 5. (A) Dependence of diffusion coefficient measured by dynamic light scattering on the protein concentrations in $\mathrm{mg} / \mathrm{ml}$ for glycosylated $\mathrm{mAb} 1$ (g1), deglycosylated mAb1 (dg1), glycosylated mAb2 
(g2) and glycosylated mAb3 (g3). Linear regression curves for each molecule are shown as dashed lines. (B) Relationship of measured from light scattering to the second virial coefficient measured by $\mathrm{x}$-ray scattering as observed here for the four Iggs and compared to the empirical relationships reported previously (supplementary material equation 9 (solid line) and 10 (dashed line)).

Figure 6. (left) Comparison between observed intensities at low angle (A, C) and wide angle (B, D) for $10 \mathrm{mg} / \mathrm{ml} \mathrm{mAb1} \mathrm{(A,} \mathrm{B)} \mathrm{and} 100 \mathrm{mg} / \mathrm{ml} \mathrm{mAB1}$ (C, D) protein solutions as measured by lab source (blue) and synchrotron (red). The intensities were scaled at $\mathrm{q}=0.0081 / \AA$.

Figure 7. The distribution function, as a function of distance for $1 \mathrm{mg} / \mathrm{ml} \mathrm{mAb1}$ (blue), deglycosylated mAb1 (red) and mAb3 (green). Molecular envelopes derived by DAMMIF from the observed intensities and the sphere model of 1HZH crystal structure. 


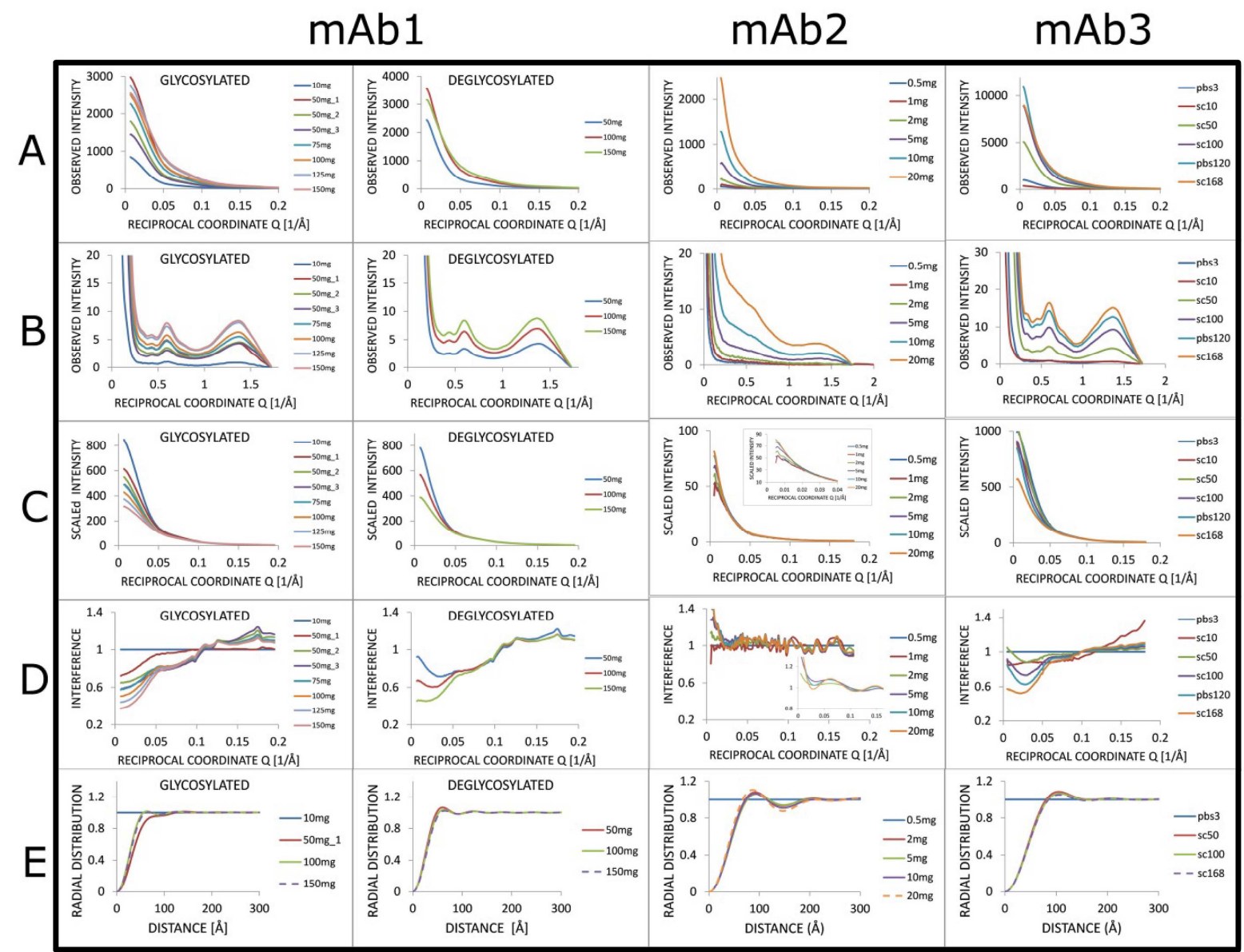




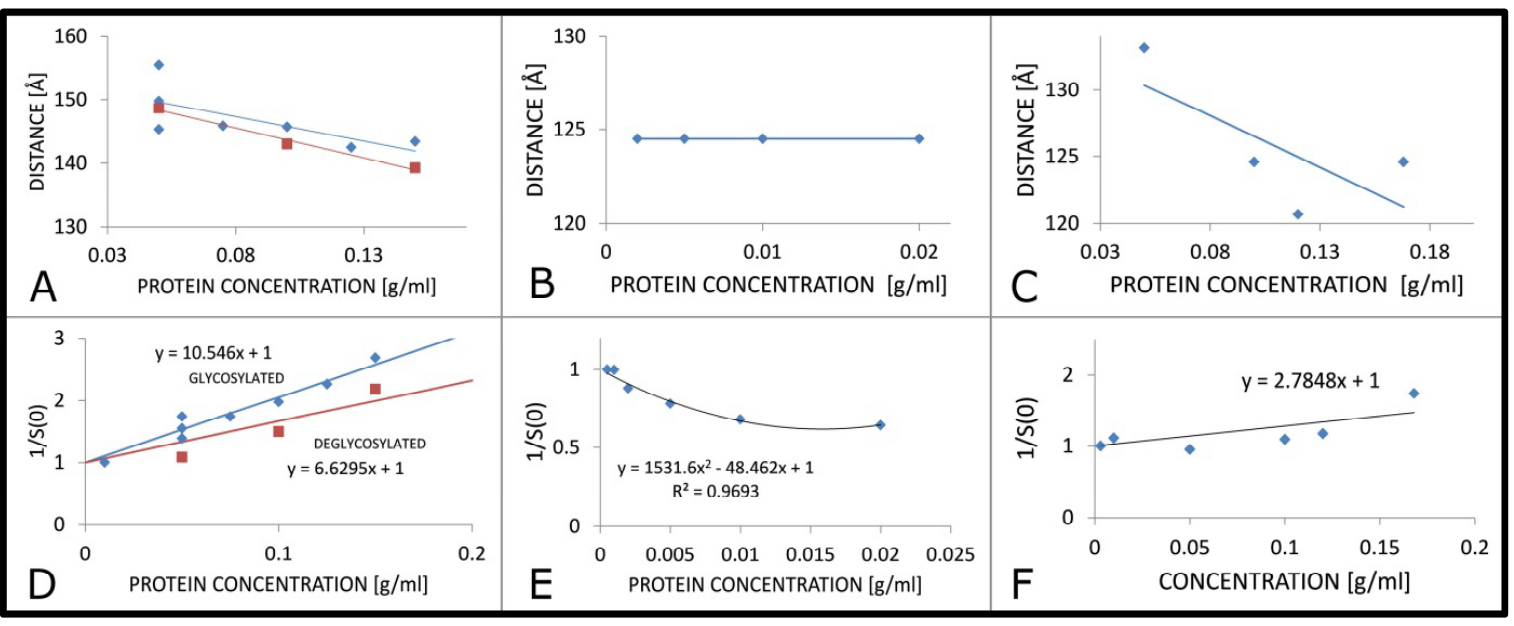



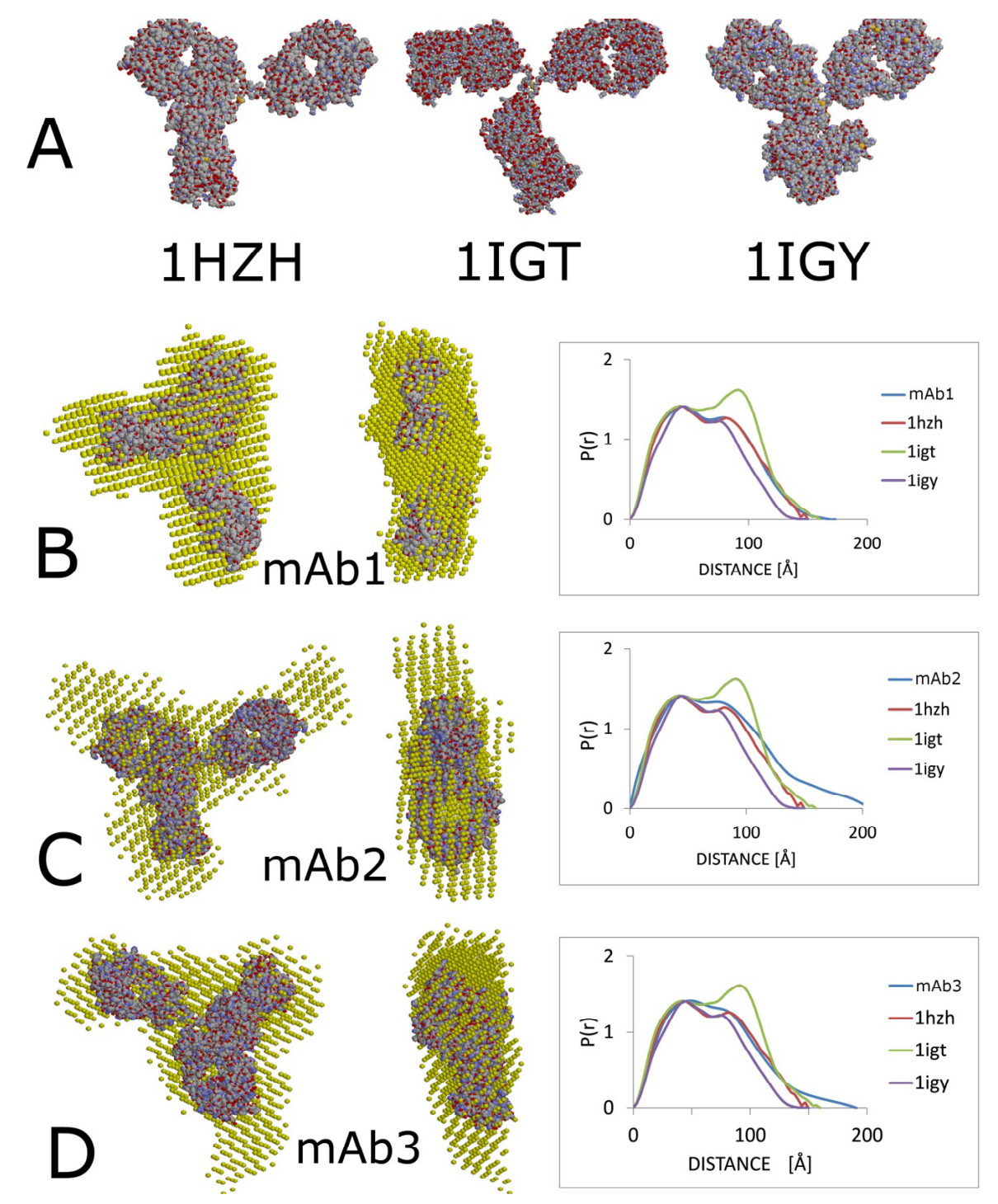


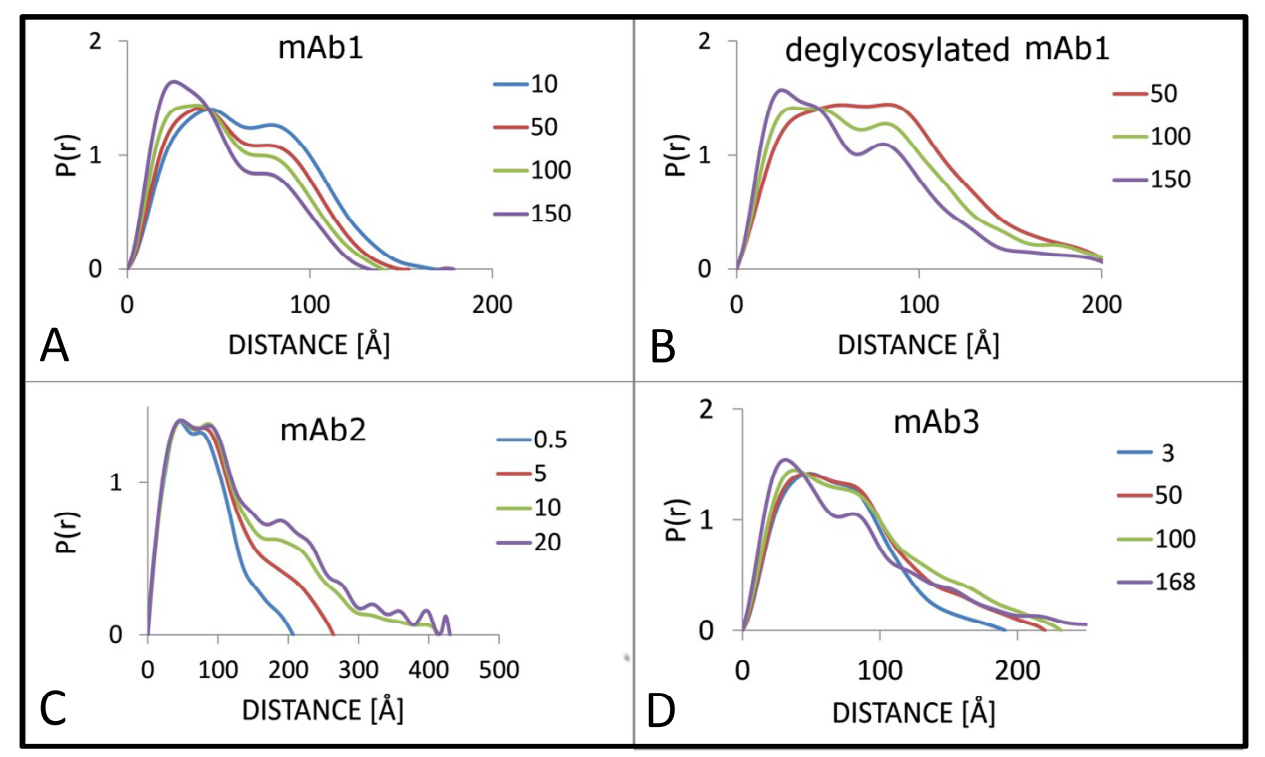




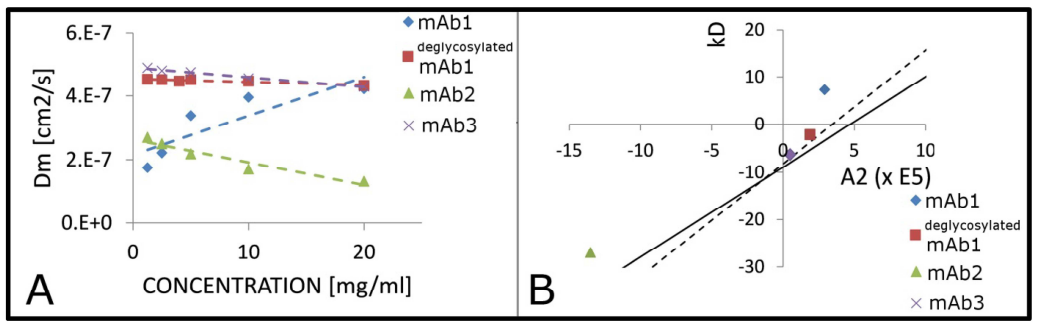




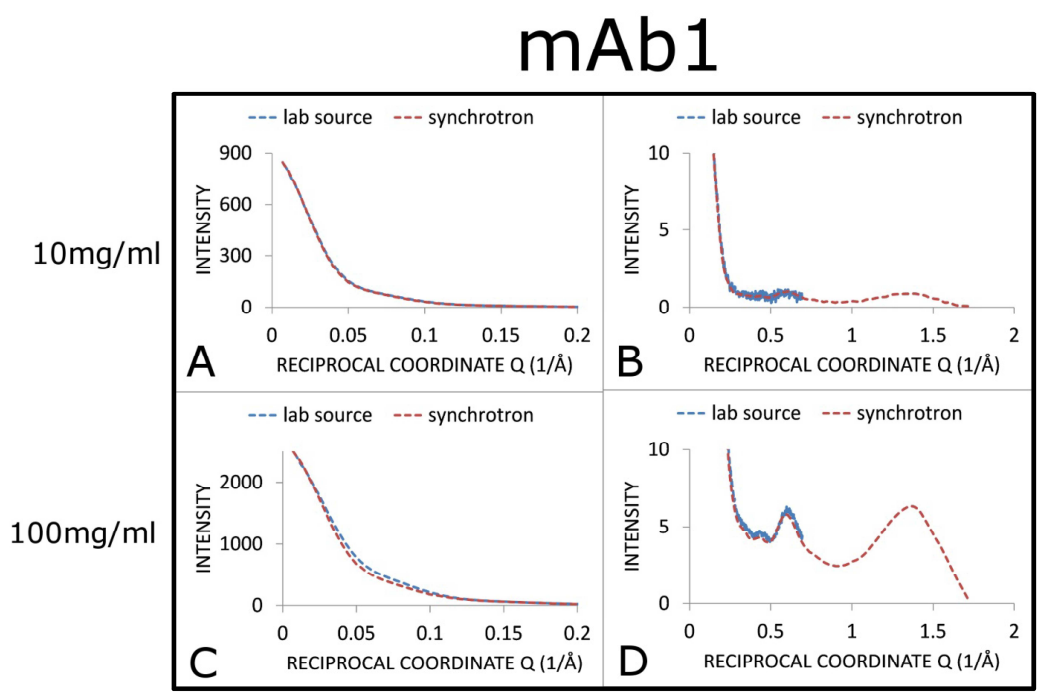




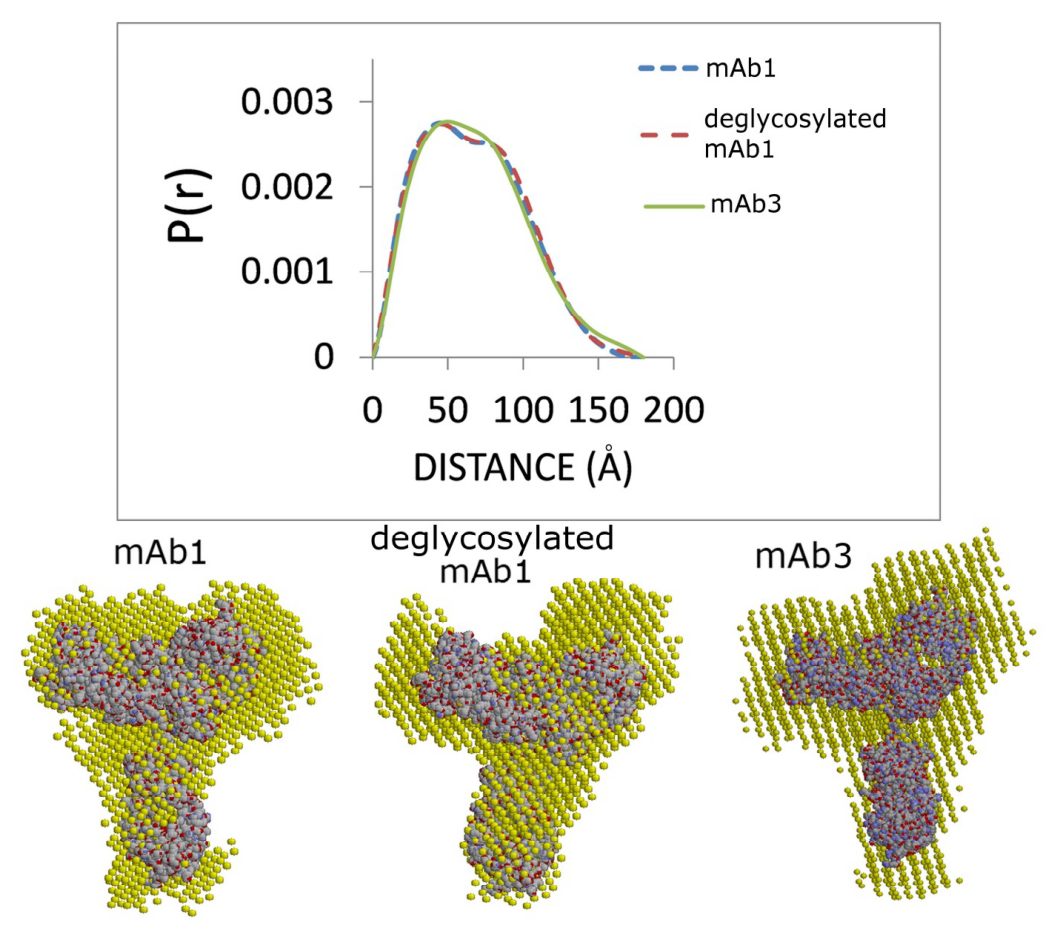

